\title{
SPIKELET STERILITY OF WHEAT IN FARMER'S FIELD IN NORTHWEST BANGLADESH*
}

\author{
M. Saifuzzaman ${ }^{1}$, Quazi Abdul Fattah ${ }^{2}$ and M. ShahiduL ISlam $^{3}$ \\ Wheat Research Centre, Bangladesh Agricultural Research Institute, \\ Gazipur-1701, Bangladesh
}

Key words: Wheat, Spikelet sterility, Grain set index, Bangladesh

\begin{abstract}
In recent decades, sporadic and/or massive occurrence of spikelet sterility in wheat has been found in almost all the wheat growing areas of Bangladesh, especially in northwest Bangladesh where spikelet sterility causes yield reductions considerably. Investigations were carried out to understand the nature and probable cause(s) regarding the spikelet sterility problem in Bangladesh. Observations included varieties of wheat, sowing dates, prevailing weather and also soil boron (B) status in farmer's field of the sterility prone areas in northwest Bangladesh. It was found that the varieties Aghrani, Akbar and Kanchan had higher percentage of spikelet sterility than Sonalika. Seven days earlier sown wheat crops had more spikelet sterility, than seven days later sown ones, and it indicated the influence of environment and/or other cause(s) on spikelet sterility; but did not indicate the direct influence of soil boron, because, no remarkable difference of soil B status existed between the sterility affected and non-affected farmer's field in those areas.
\end{abstract}

\section{Introduction}

Wheat, Triticum aestivum L., is one of the oldest cereal crops used by human beings. In Bangladesh, wheat is the second most important cereal crop after rice. Wheat production in the country has increased from about 0.1 million tons in early 1970's to 1.9 million tons in 1999 due to the cultivation of high yielding varieties after mid 70's.

In Bangladesh, sterility in wheat was first noticed in 1974 at Thakurgaon in the wheat variety Tanori-71. In 1986-1987 and 1987-1988 growing seasons, widespread spikelet sterility in two wheat varieties, Kanchan and Sonalika, were noticed mainly in farmer's field in the greater Rangpur and Dinajpur districts within northwest Bangladesh. Since then, wheat sterility has been observed in Kanchan for some years, but not in every year, in farmer's field in different areas.

Sterility of wheat is not a problem of Bangladesh alone but it is a widespread problem in the subtropical wheat growing areas of Asia. Problem areas so far identified include Orissa, Terai regions of West Bengal and Assam (Tandon and Naqvi 1992), eastern Terai region and other parts of Nepal (Subedi et al. 1993), northern Thailand (Rerkasem et al. 1989), Heilongjiang (Li et al. 1978) and Yunnan (Yang 1992) provinces of China. The aim of this study is to find out the probable cause(s) of spikelet sterility in wheat in Bangladesh, especially in northwest Bangladesh.

\section{Materials and Methods}

During 1989-'90 growing season, observations at farmer's field of the sterility affected areas of greater Rangpur and Dinajpur districts were carried out at the maturity stage of four wheat varieties such as Sonalika, Aghrani, Akbar and Kanchan. During this study, 20 wheat spikes, irrespective of varieties and sowing dates, were collected from each visited spot of sterility affected and non affected farmer fields. Soil samples at a depth of $0-20 \mathrm{~cm}$ were also collected

\footnotetext{
*Part of corresponding author's Ph. D. thesis work. ${ }^{1}$ Corresponding author, E-mail: <szamanwrc@ yahoo.com> ${ }^{2}$ Department of Botany, University of Dhaka, Dhaka-1000, Bangladesh. ${ }^{3}$ BARI, Gazipur-1701, Bangladesh.
} 
from the same visited fields for soil boron analysis. Sterility and grain set index (GSI) percentage were determined as per Rerkasem (1990) as shown below:

$$
\begin{aligned}
\text { Sterility }(\%) & =\frac{(20-\mathrm{GS})}{20} \times 100 \\
\text { GSI }(\%) & =\frac{\mathrm{GS}}{20} \times 100
\end{aligned}
$$

where 20 is considered as constant grain sets (GS) number and GS is the actual grain sets in the basal two florets of 10 central $\left(5^{\text {th }}\right.$ to $\left.14^{\text {th }}\right)$ spikelet of each spike.

Hot water soluble (hws) and/or available soil boron in ppm was determined by hot water extracting using Azomethine-H colour development reagent (Wolf 1974, Odom 1980). Quantification is performed by atomic absorption spectroscopy. The results of soil boron content have been presented in Fig. 3. Daily maximum and minimum air temperature, relative humidity, sunshine hour and rainfall data were collected from Rangpur agro-metrology station and presented in Fig. 4 along with the important crop developmental stages.

\section{Results and Discussion}

Percentage of spikelet sterility varied with the different wheat varieties in the farmers' field of sterility-prone areas in 1989-'90. Highest sterility was observed in varieties Aghrani and Akbar followed by Kanchan. Lowest sterility was noticed in Sonalika (Fig. 1).

Percentage of spikelet sterility also varied with the sowing dates. Seven days early planting than the cut off optimum sowing date $\left(30^{\text {th }}\right.$ November) had more spikelet sterility than wheat sown in seven days late (Fig. 2).

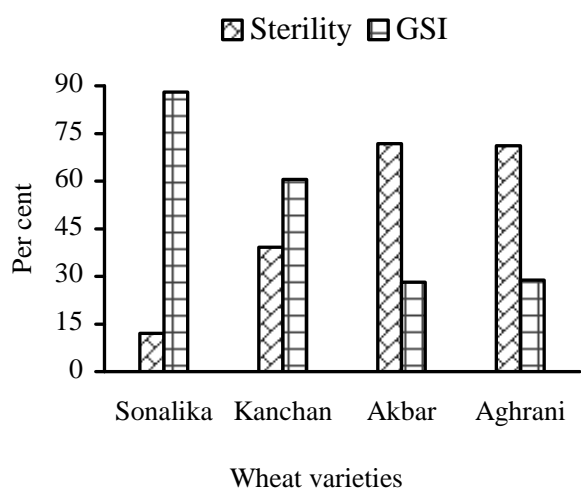

Fig.1. Spikelet sterility and grain set index in different wheat varieties.

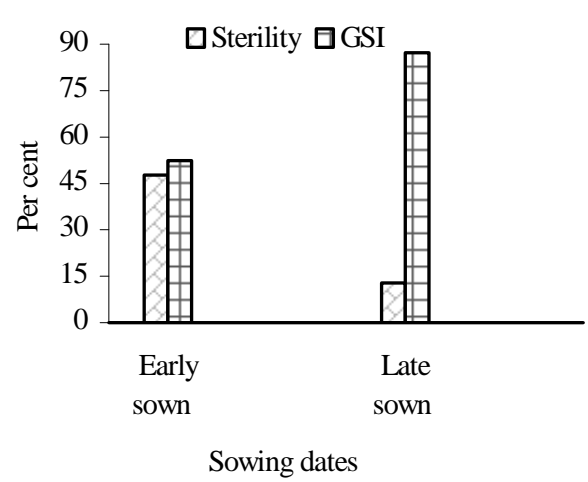

Fig. 2. Spikelet sterility and grain set index in early and late sown wheat.

Varietal differences in terms of spikelet sterility observed in the sterility prone areas of northwest Bangladesh during the farmers' field survey agrees well with the findings of Tandon and Naqvi 1992, Subedi et al. 1993. Joshi and Sthapit (1996) who mentioned that spikelet sterility in different wheat varieties differed probably due to difference in genetic characters. The present study indicated that spikelet sterility happens due to the differences of plant developmental stages among the varieties and also environmental conditions which prevailed during the reproductive developmental stages. 
Presence of boron in soil ranged from 0.06 to $0.14 \mathrm{ppm}$ at farmer's field with and without spikelet sterility in the sterility prone areas (Fig. 3). In Bangladesh, the critical level of available boron in soil has been reported to be $0.2 \mathrm{ppm}$ (Islam and Hossain 1986). Rerkasem et al. (1989) reported that poor grain set in wheat in Thailand was due to low hot water soluble boron, as low as $0.08-0.12 \mathrm{ppm}$ in soil. In the present study, soil boron status indicated that boron has no impact on the spikelet sterility because there is no remarkable difference of boron status in sterility affected and non affected fields, and the range was found 0.06 to $0.12 \mathrm{ppm}$ and 0.6 to $0.14 \mathrm{ppm}$ respectively. So, the results indicated that soil boron had no direct role in occurrence of spikelet sterility of wheat in Bangladesh. Boron availability to plants is known to be influenced by environmental conditions such as high humidity (Huang et al. 2001). Rawson (1996) suggested that one of the effects of environmental stresses is to prevent transpiration pull and which is associated with the uptake and movement of B in plant parts especially in the reproductive growth centers, and as a result spikelet sterility may occur due to low boron in plant tissue. During the present study low light intensity or short sunshine period due to foggy weather, humidity and pollution may have low boron in wheat tissue leading to sterility.

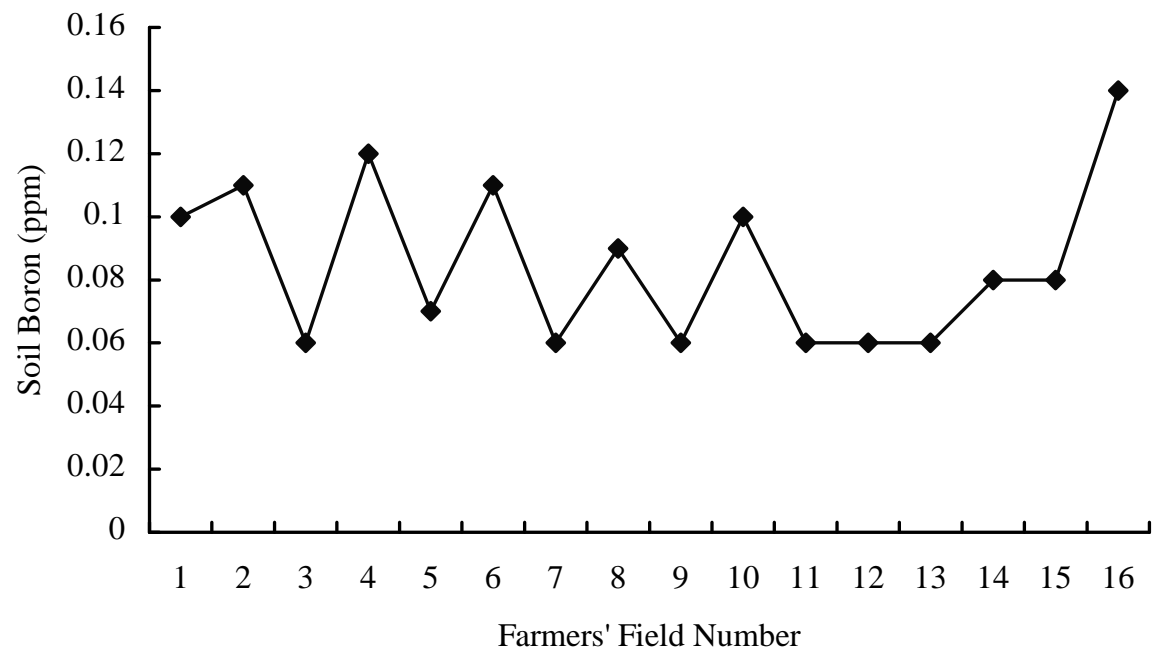

Fig. 3. Soil boron status at different farmer's field in the sterility prone areas of northwest Bangladesh.

Subedi et al. (1993) observed very low sterility and low number of spikelet in RR-21 (Sonalika) during farmers' field survey in Nepal. In the present observation, it has been observed that Sonalika had lowest spikelet sterility than the other three varieties, and Sonalika had also lowest spikelet number and thus the present observation is in accord with the findings of Subedi et al. (1993). One of the causes of spikelet sterility in wheat and other cereals could be due to non-availability of necessary amount of assimilates and/or nutrients in the demanding zone due to environmental stresses during reproductive and grain developmental stages.

Environmental conditions prevailed in the sterility prone areas in 1989-'90 showed that during the period from the end of December to third week of January had high humidity and low sunshine hour that resulted low light intensity in comparison to the period from end of January to second week of February (Fig. 4). Wheat sown seven days earlier had its critical crop growth period during high humidity and low light conditions, and, as a result, spikelet sterility was more observed in comparison to wheat sown late (Fig. 4). 
Grain set index or basal floret fertility of two basal florets $\left(\mathrm{F}_{1}\right.$ and $\left.\mathrm{F}_{2}\right)$ of ten central spikelets is a recent approach for determining the failure of grain set in wheat (Rerkasem 1990). Grain set index indicates the severity of spikelet sterility because grain set starts from the middle of a spike and progresses towards the apex and also the base of the spike (Mishra and Mohapatra 1987).
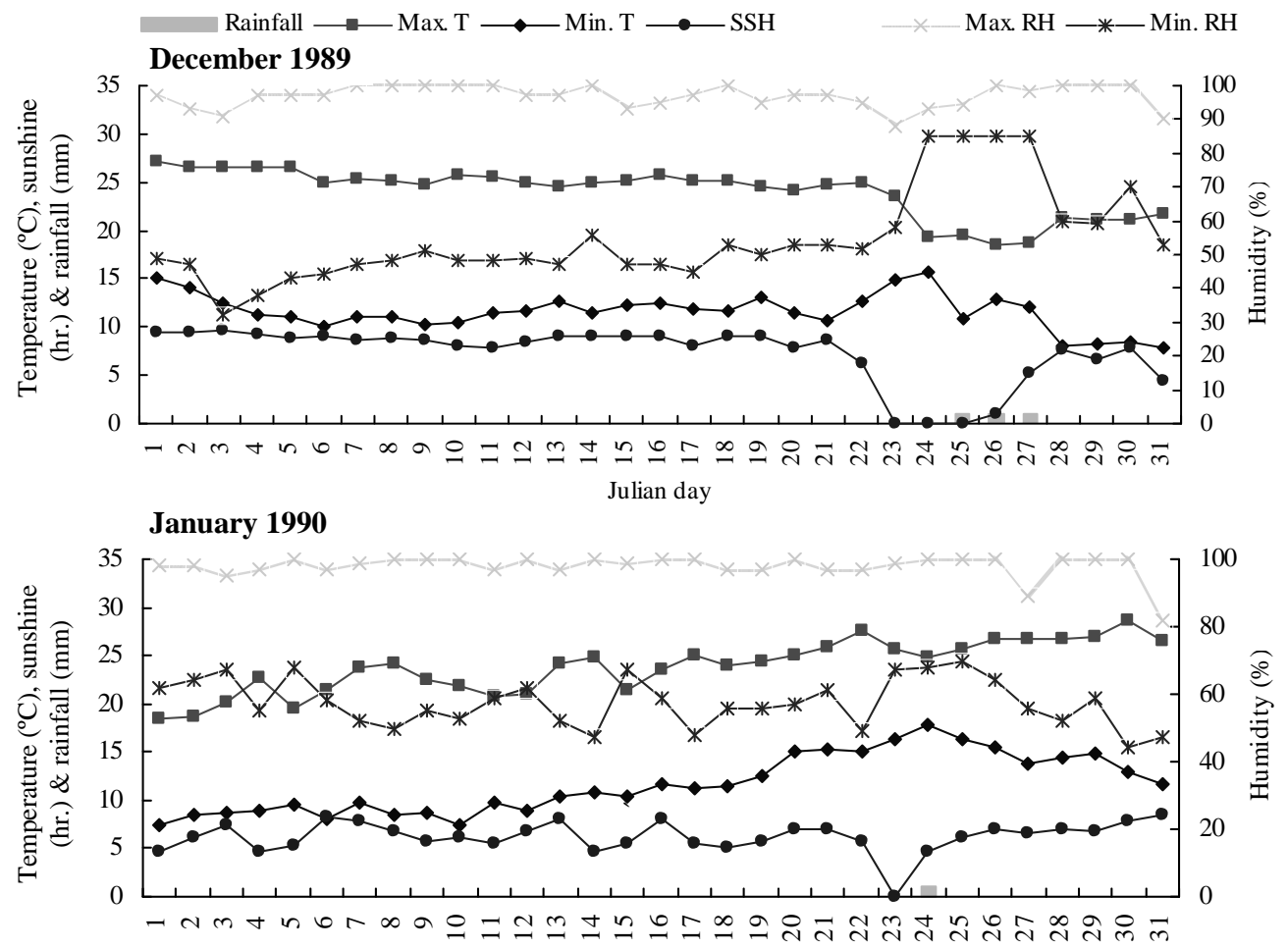

February 1990

Julian day

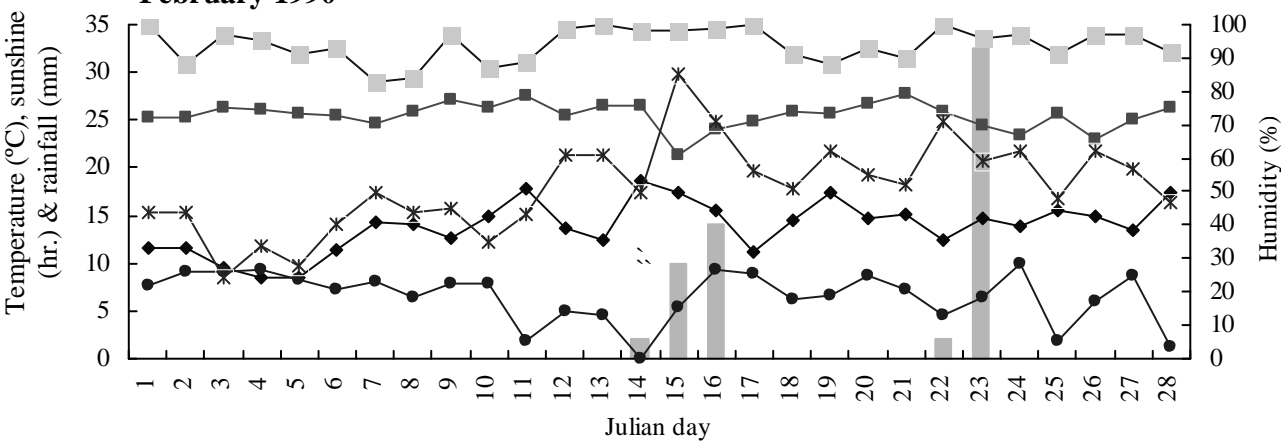

Fig. 4. Weather of 1989-'90 in the sterility prone areas of Bangladesh.

Max. T and Min. T = Maximum and minimum temperature respectively. Max. $\mathrm{RH}$ and

Min. $\mathrm{RH}=$ Maximum and minimum relative humidity respectively and $\mathrm{SSH}=$ Sunshine hour.

Grain set index value differed with different wheat varieties (Fig. 1). The variety Sonalika had highest grain set index value and it was followed by Kanchan. Lowest grain set index value was noticed in Akbar and Aghrani in 1989-'90. Grain set index value also differed with sowing dates. Seven days early planted wheat had lower grain set index value than wheat sown seven days late (Fig. 
2). From the farmers' field observations on four varieties of wheat, Sonalika, Kanchan, Akbar and Aghrani, it can be concluded that differences are found in terms of spikelet sterility among the wheat varieties.

Campbell and Read (1968) mentioned that high humidity and low light intensity together affected grain set of wheat probably due to less transpiration that ultimately affected the translocation of assimilates. They also mentioned low light alone affected the grain set, but high humidity plus low light intensity affected grain set more, and there was less GSI due to the latter.

Sowing date variation in respect of GSI in farmers' field probably related also with the plant developmental stages and environment. Fischer (1985) stated that continuous high humidity (70\%) around meiosis could reduce grain set in certain wheat cultivars. Soil analysis indicated that there was no remarkable difference in soil boron among the sterility affected and non-affected farmers' field and, as a result, there seemed to be no influence of soil B on the grain set index of wheat in Bangladesh (Fig. 3).

So, it can be said that there is no clear indication that boron causing, controlling and/or reducing spikelet sterility in wheat in Bangladesh. Moreover, there is a relationship between environment, like high humidity and low light intensity due to fogginess and phenological development of wheat at reproductive stage. There may also be a chance of genotype and environmental interactions in causing spikelet sterility. It may happen due to the differences of phenological differences among the varieties. Besides high humidity and low light intensity, other environmental parameters like high temperature caused spikelet sterility as mentioned by a number of researchers; but there is very little chance of attaining temperature of $32^{\circ} \mathrm{C}$ or more during reproductive stage (last week of January to middle of February) in the sterility prone areas of Bangladesh. In the context of Bangladesh low temperature, rather than high temperature, cause spikelet sterility in wheat, because in the sterility prone areas minimum temperature of $10^{\circ} \mathrm{C}$ and even below prevails at reproductive stage if seeds are sown in between November 15 and 30, the recommended optimum time for sowing. In that case, reproductive stage (especially pre-boot to eight days and/or booting to eight days) will attain from end of December to middle of January. But in northwest Bangladesh most of the wheat sowings are done during 10 - 20 December. As a result of this comparatively late sowing the reproductive stage appears at a time when the temperature is above $10^{\circ} \mathrm{C}$ and thus there is very little chance to have sterility due to low temperature. Another factor responsible for the occurrence of spikelet sterility in the farmers' field may be due to water stress and/or waterlogging. In Bangladesh almost all of the wheat crops are grown under irrigated condition and there is almost very little scope of spikelet sterility due to water stress; but there is some probability of mild waterlogging and/or excess moisture in the soil due to irrigation plus rains concurrently at booting to heading stages and that can cause spikelet sterility.

\section{References}

Campbell, C.A. and D.W.L. Read. 1968. Influence of air temperature, light intensity and soil moisture on the growth, yield and some growth analysis characteristics of Chinook wheat grown in the growth chamber. Can. J. Plant Sci 48: 299-311.

Fischer, R.A. 1985. Physiological limitations to producing wheat in semitropical and tropical environments and possible selection criteria. In: Wheat for More Tropical Environments. pp. 209-230. Proceedings of the International Symposium. September 24-28, 1984. UNDP/CIMMYT: Mexico.

Huang, L., J. Pant, R.W. Bell and B. Dell. 2001. Boron supply to wheat (Triticum aestivum L. cv. Wilgoyne) ears whilst still enclosed with leaf sheaths. J. Expt. Bot. 62(361): 1731-1736.

Islam, M.S. and K.M. Hossain. 1986. Nutrient requirement for non-irrigated and irrigated wheat. In: Third National Wheat Training Workshop. Bangladesh Agricultural Research Institute, Wheat Research Centre and CIMMYT/CIDA Wheat Program. August 4-5, Joydebpur, Gazipur. pp. 74-90. 
Joshi, K.D. and B.R. Sthapit. 1996. Genetic variability and possible genetic advance for sterility tolerance in wheat (Triticum aestivum L.) through breeding. In: Sterility in Wheat in Subtropical Asia: Extent, causes and solutions (H. M. Rawson and K. D. Subedi. Eds.), Aust. Centre for International Agric. Res. Proceed. No.72:135-143.

Li, W.H., M.C. Kui, N.S. Chao, M.P. Jern, C.R. Li, W.J. Chu and C.L. Wang. 1978. Studies on causes of sterility of wheat. J. Northeastern Agric. College. 3: 1-19.

Mishra, S.P. and P.K. Mohapatra. 1987. Soluble carbohydrates and floret fertility in wheat in relation to population density stress. Ann. Bot. 60(3): 269-277.

Odom, J.W. 1980. Kinetics of hot-water soluble boron soil test. Comm. Soil Sci. Plant Anal. 11(7): 759-769.

Rawson, H.M. 1996. The developmental stage during which boron limitation causes sterility in wheat genotypes and the recovery of fertility. Aust. J. Plant Physiol. 23: 709-717.

Rerkasem, B. 1990. Genotypic variations in the response to boron in wheat and barley. International Soil Congress, Kyoto. 12-18 August. pp. 1-2 .

Rerkasem, B., D.A. Saunders and B. Dell. 1989. Grain set failure and boron deficiency in wheat in Thailand. J. Agric. 5(1): 1-10.

Subedi, K.D., C.B. Budhathoki, M. Subedi and J.K. Tuladhar. 1993. Survey and research report on wheat sterility problem. Working paper no. 93/49. Lumle Agric. Res. Centre. Pokhara, Nepal.

Tandon, J.P. and S.M.A. Naqvi. 1992. Wheat varietal screening for boron deficiency in India. In: Boron deficiency in wheat (C.E. Mann and B. Rerkasem Eds.), Wheat special report, CIMMYT, Mexico. 11: 76-78.

Wolf, B. 1974. Improvements in the Azomethine-H method for the determination of boron. Comm. Soil Sci. Plant Anal. 5(1): 39-44.

Yang, Y.H. 1992. Wheat boron deficiency in Yunnan, China. In: Boron Deficiency in Wheat (C. E. Mann and B. Rerkasem Eds.). CIMMYT, Mexico.

(Manuscript received on 16 June, 2008; revised on 2 September, 2008) 